\title{
Spatial and socioeconomic inequalities in the availability of community health centres in the Jakarta region, Indonesia
}

\author{
Fikriyah Winata, Sara L. McLafferty \\ Department of Geography and Geographic Information Science, University of Illinois at Urbana- \\ Champaign, Natural History Building, Urbana, IL, USA
}

\begin{abstract}
In the late 1960s, Indonesia established community health centres (CHCs) throughout the country to provide basic healthcare services for the poor. However, $\mathrm{CHC}$ expenditures and investments vary widely at the sub-provincial level, among administrative areas known as cities and regencies, raising concern that facilities and services do not correspond to population needs. This study aimed to examine spatial and socioeconomic inequalities in the availability of CHCs in the Jakarta region. We used spatial and statistical analysis methods at the village level to investigate these inequalities based on $\mathrm{CHC}$ data from the Ministry of Health and socioeconomic data from Indonesia Statistics. Results show that
\end{abstract}

Correspondence: Fikriyah Winata, Department of Geography and Geographic Information Science, University of Illinois at UrbanaChampaign, Natural History Building, 1301 W. Green St., Urbana, IL 61801, USA.

E-mail: fwinata2@illinois.edu

Key words: Community health centres; healthcare workers; socioeconomic inequality; spatial analysis; Jakarta; Indonesia.

Acknowledgements: the authors would like to express gratitude to the anonymous reviewers for providing critical insights. We also thank the editors for their thoughtful editing of the final manuscript.

Contributions: FW, conceptualized the idea and topic, data collecting and analyzing, model interpretation, manuscript writing and reviewing, and reference search; SLM, conceptualized the idea and topic, model interpretation, manuscript writing and reviewing, and reference search.

Conflict of interests: the authors declare no potential conflict of interests.

Supplemental material: supplemental material for this research is available upon request to the first author.

Received for publication: 27 January 2021.

Revision received: 6 June 2021.

Accepted for publication: 7 June 2021.

CCopyright: the Author(s), 2021

Licensee PAGEPress, Italy

Geospatial Health 2021; 16:982

doi:10.4081/gh.2021.982

This article is distributed under the terms of the Creative Commons Attribution Noncommercial License (CC BY-NC 4.0) which permits any noncommercial use, distribution, and reproduction in any medium, provided the original author(s) and source are credited.
CHCs and the healthcare workers within them are unevenly distributed. In areas with high need, the availability of CHCs and healthcare workers were found to be low. There is a mismatch in healthcare services and delivery for low-income, unemployed populations at the village level that needs to be addressed. The findings discussed in this paper suggest that Jakarta Department of Health should coordinate with local public health districts to determine locations for new CHCs and assign healthcare workers to each $\mathrm{CHC}$ based on need as this would improve access to essential health services for the low-income population.

\section{Introduction}

Uneven geographical distribution of healthcare services is the key issue in low-resource settings (Entwisle et al., 1997; Awoyemi et al., 2011; Yao et al., 2012; Yao et al., 2013; Strasser et al., 2016). In Indonesia, where public and private healthcare systems are intertwined (Yusvirazi et al., 2018) with most approaches leaning towards the public system (Heywood and Harahap, 2009a), government-funded and managed healthcare services are crucial in efforts to improve public health, especially for the country's large, low-income population. Most developing countries experience inequalities in geographical access and availability of health services. Research on the number of facilities (Munoz and Kallestal, 2012; Woldemichael et al., 2019), on healthcare professionals (Acharya and Cleland, 2000; Paul and Edwards, 2018) and on type of services provided, have revealed large-scale disparities in health service availability relative to population needs, e.g., with respect to child immunization (Acharya and Cleland, 2000), reproductive health services (Entwisle et al., 1997), maternal and neonatal care (Abdulrahim and Bousman, 2019; Ruktanonchai et al., 2018) and specialized services such as HIV testing (Yao et al., 2012; Yao et al., 2013).

Indonesian government-based healthcare facilities, such as public hospitals, community health centres (CHCs) and Army and Police clinics are pivotal to providing health services for the lowincome populations. $\mathrm{CHCs}$ are primary healthcare facilities that everyone with Indonesian citizenship can access (Yusvirazi et al., 2018). The service is free for people covered by the Social Security Administration for Health (BPJS) and others only need to pay a small registration fee (less than USD 0.5 in 2021). However, compared to other countries in Asia and the Pacific, the ratio between the number of $\mathrm{CHCs}$ and those who need them is relatively low in Indonesia (Mahendradhata et al., 2017).

When first established in the 1960s, CHCs were set up to provide basic healthcare for the poor across the country (Frederick and Worden, 1993; Heywood and Harahap, 2009a). The initiative expanded in the 1980s as the Ministry of Health (MOH), Republic of Indonesia increased both the number of $\mathrm{CHCs}$ and the number of healthcare workers within them (van de Walle, 1994). In the 
mid-1990s, this had resulted in more than 7000 CHCs across Indonesia, and because of this increase, the average population accessing them decreased from 96,000 in 1968 to 30,000 in 1995 (Heywood and Choi, 2010). Today, however, financial constraints have become a major impediment to $\mathrm{CHC}$ availability. Indonesia's total healthcare expenditure in 2016 was USD 112 per capita [or $3.12 \%$ of the country's gross domestic product (GDP)] (World Bank, 2019). This expenditure was unevenly distributed among provinces and regencies, which has been 'a long-standing concern' in Indonesia (van de Walle, 1994). Across cities in Indonesia, healthcare expenditures vary widely (Heywood and Harahap, $2009 \mathrm{~b}$ ), and disparities have increased especially after Indonesia implemented administrative decentralization in 2001 (Heywood and Choi, 2010; Mulyanto et al., 2019b).

At the sub-provincial level, cities and regencies are further subdivided into districts. Districts consist of multiple villages/subdistricts, which may or may not contain village-level CHCs, and people are required to access the $\mathrm{CHCs}$ located within the district they live in. Each district is required to have at least one $\mathrm{CHC}$, while districts in Jakarta typically have more CHCs ranging from 3 to 13 , while the number of $\mathrm{CHCs}$ within each village ranges from 0 to 4 . Thus, although every district has a $\mathrm{CHC}$, not every village has one and this exacerbates the geographical inequality of $\mathrm{CHCs}$. Typically, CHCs at the district level have more healthcare workers and provide inpatient care, while village-level CHCs often struggle to find healthcare workers and their services are therefore very limited. Among the 262 villages in the Jakarta region, only $11(4 \%)$ and $14(5 \%)$ villages have 4 and $3 \mathrm{CHCs}$ respectively. A majority of villages have $1 \mathrm{CHC}(49 \%)$, and $53(20 \%)$ have no $\mathrm{CHC}$. Although people who lack a $\mathrm{CHC}$ in their village can cross village boundaries to use another $\mathrm{CHC}$ in their district, this might require time and high travel costs. Central, South and East Jakarta all have a high density of healthcare workers. For example, the number of healthcare workers within each $\mathrm{CHC}$ varies between 0 and 94, while the number of general practise doctors (GP) and nurses ranges from 0 to 20 and from 0 to 77 , respectively.

A growing body of literature analyses geographical inequalities in health service availability in developing countries ranging from Mozambique (Yao et al., 2012) to India (Shaw and Sahoo, 2020) to Bhutan (Jamtsho et al., 2015). Using increasingly robust geospatial methods to measures spatial accessibility, these studies document wide geographical inequalities in health service availability and supply. However, with a handful of exceptions (e.g. Wang et al., 2018), few studies have investigated how inequalities in spatial access to services in developing countries are patterned according to class, age, and other social dimensions that affect health care need and vulnerability. We aimed to addresses this gap by investigating the associations between need and spatial availability of community health centres in the Jakarta region.

The objective of this study was to analyse social and spatial inequalities in the availability of CHCs in the Jakarta region, one of the economic and population hubs of Indonesia. Following the example of research in both high income and low-income countries including Australia (McGrail and Humphreys, 2015), China (Xiong and Luo, 2017), Iran (Hoseini et al., 2018), India (Ranga and Panda, 2014; Shaw and Sahoo, 2020), Mozambique (Yao et al., 2012), Rwanda (Munoz and Kallestal, 2012) and Sudan (Macharia et al., 2017), we used spatial analysis and statistical methods to analyze the mismatch between $\mathrm{CHC}$ services and the low-income populations most reliant on $\mathrm{CHCs}$ for health care. This is the first study to analyse CHCs at the village level - geographic variation at these more localized scales has not been studied - considering the locations of low-income communities. This analysis is important for policy makers in determining where to place and build new CHCs in the future.

\section{Materials and methods}

\section{Study site}

The geographical area studied was the Jakarta region, which is situated around the latitude $6^{\circ} 12^{\prime} 0.00$ ' $\mathrm{S}$ and longitude $106^{\circ} 48^{\prime} 59.998^{\prime \prime}$ E (Figure 1). This area is important for the analysis because of its high concentration of population, economy, business, central government activities, and its uneven spatial distribution of low-income population. Jakarta is the most highly populated and densely settled region of Indonesia with 15,900 people per $\mathrm{km}^{2}$ (BPS, 2020) which means that the impact of inequality with respect to service availability is potentially very large.

\section{Data}

The CHC dataset was gathered from the $\mathrm{MOH}$ in September 2017. Point locations of $327 \mathrm{CHCs}$ were obtained from the MOH's WebGIS, (http://gis.depkes.go.id/), which is now integrated with the Ina-Geoportal (http://portal.ina-sdi.or.id/geoportal). We excluded CHCs in Kepulauan Seribu district - as this district consists of thousands of tiny islands separated from the mainland. The point data set was expanded by the addition of information on the number of healthcare workers, pharmacy, and non-health staff within each CHC from the MOH's Board of Development and Empowerment Human Resources of Health (BPPSDM). All general practitioners (GPs), midwives, and nurses within each $\mathrm{CHC}$ were extracted and used as supply indicators since they are the main primary care providers within the $\mathrm{CHCs}(\mathrm{MOH}, 2014)$, and each $\mathrm{CHC}$ in the Jakarta district is required to contain at least one of them on the staff (Heywood and Harahap, 2009a). There are two types of CHCs, i.e. those providing hospital care and those that only provide outpatient care (Figure 1). Among the $327 \mathrm{CHCs}$ in Jakarta, only 51 (16\%) offer hospital beds, and those CHCs have more healthcare workers, including a higher percentage of nurses. Few CHCs $(7 \%)$ have medical specialists, reflecting $\mathrm{CHCs}^{\prime}$ emphasis on primary care.

Data on spatial and socioeconomic inequality of access to CHCs were obtained from the Indonesia Statistics (BPS), Indonesia Data Portal (IDP) (http://data.go.id), and the MOH (IDP, 2017a, 2017b; MOH, 2017). Since middle- and high-income people in Jakarta are likely to go to private clinics and hospitals, we focused on those most in need of the CHC services, i.e. the lowincome population. To represent this population by village, we used three variables: i) unemployed which includes people who lack or are looking for formal employment; ii) people with lowincome occupations based on data from the International Labor Organization (ILO, 2015); iii) households with a letter poverty, a certificate enabling the receipt of government rice subsidies and reduced college tuition for children's education. Although these three measures of low-income population are correlated, each represents different dimensions of Indonesia's poverty population and need for CHCs.

We also considered population density by village as a variable because it is a fundamental indicator of need for services. Figure 2 
maps the distribution of the CHCs overlaid with the population per $\mathrm{km}^{2}$ in each village, which reveals a broad correspondence between $\mathrm{CHC}$ locations and local population density.

\section{Spatial and statistical analysis}

Kernel density estimation (KDE) was used to estimate the uneven geographic density of CHCs in the region and the densities of GPs, midwives, and nurses. KDE estimates the local density of points (CHCs) at each location in the study area based on a weighted function of distance and generates a continuous surface 'heat map' which indicates areas of high and low CHC availability by colour (Guagliardo, 2004; Higgs, 2004; Yang et al., 2006). Note that $\mathrm{KDE}$ is not an interpolation method, but rather a method for estimating the spatially-varying density or intensity of points per area under investigation. In analysing the spatial distribution of workers, each point was weighted by the respective number of workers at the CHC. The choice of bandwidth (kernel radius) is pivotal in generating the surface (Shi, 2010). We experimented with many options and found that the default bandwidth of ArcGIS (ESRI, Redlands, CA, USA), which uses the spatial variant of Silverman's method (ESRI, 2017), generated appropriate results for our localized, village-level analysis. To better understand where the low-income population is concentrated, we used the local indicator spatial autocorrelation (LISA) method in GeoDa software (GeoDa, 2017) to detect spatial clusters for each of the three measures: unemployment, low-income occupations, and letters of poverty. This method identified nearby villages that have similar values for low-income population according to Local Moran's $I$ statistic (Anselin, 1995). Because the study area is heterogeneous, for spatial weights, we used k-nearest neighbours distance weights with five neighbours.

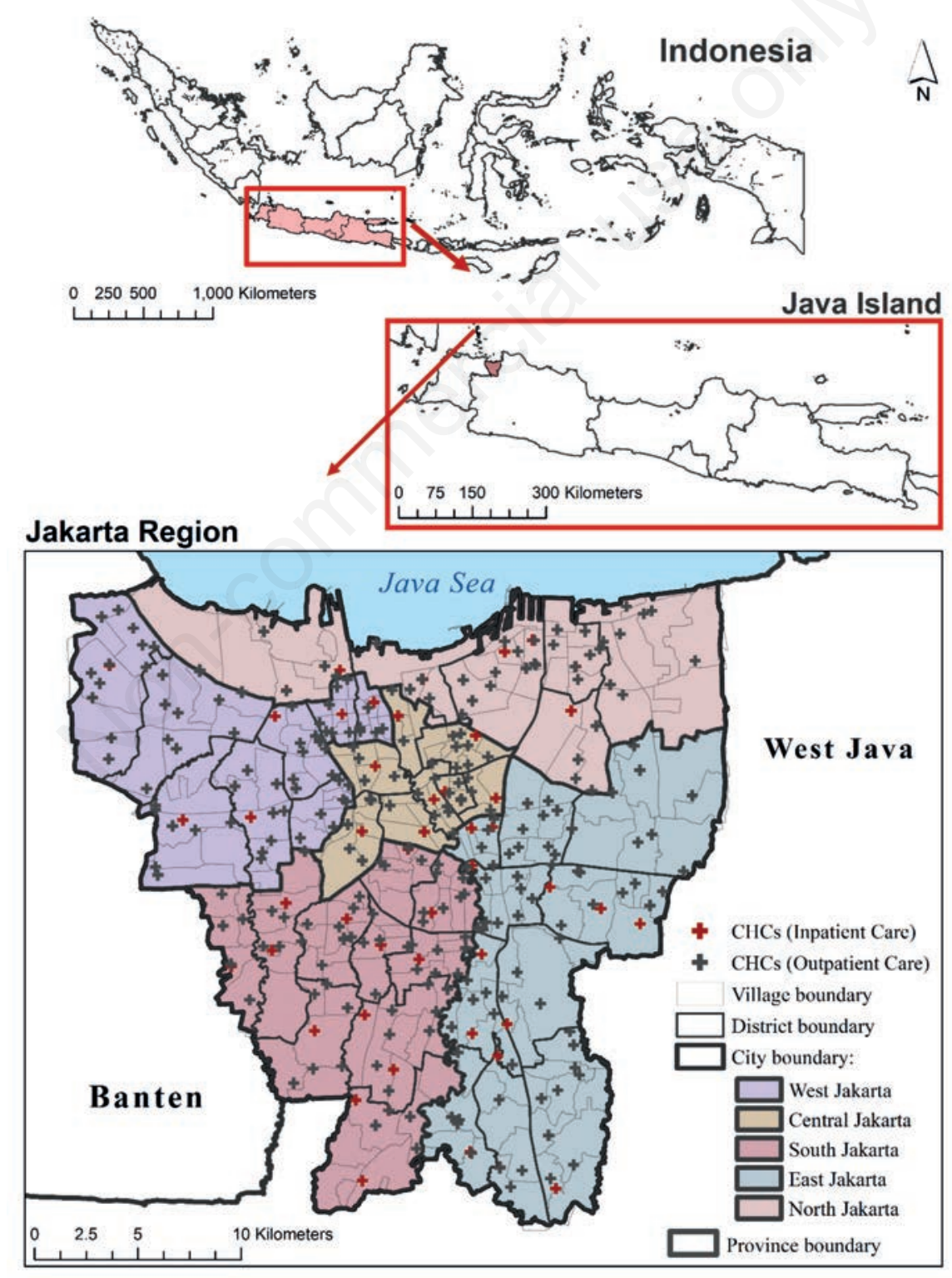

Figure 1. Distribution of community health centres in the Jakarta Region. 
A spatial lag regression model was estimated to examine the relationship between the density of CHCs in each village and the low-income variables. The response variable in this model is the density value of CHCs, which was extracted at the centroid of each village. Since the density values are spatially autocorrelated, we employed the spatial lag model which considers such autocorrelation in the response variable. The predictor variables used were: i) the number of unemployed; ii) the number of letters of poverty generated by the village office in each village; and iii) the number of people with low-income occupations. We examined Pearson's correlations between all predictor variables to check for multicollinearity. The bivariate correlations (r) between unemployed and letters of poverty and between letters of poverty and lowincome occupations were both very small. However, unemployed and low-income occupation were highly correlated $(\mathrm{r}=0.78)$. Due to the collinearity between these two variables, we excluded the number of people with low-income occupations in the multiple spatial regression model and kept the numbers of people unemployed since this variable is based on rigorous data collection by BPS. After estimating models separately for each low-income variable (Models 1-3), we estimated a multiple regression model that included population density of the village as an additional predictor variable. The equations of the spatial lag models were:

Model 1:

Model 2:

Model 3:

Model 4 (full model):

$$
\begin{aligned}
& y=(\rho) \mathrm{W}_{\mathrm{y}}+X_{1}\left(\beta_{1}\right)+\varepsilon \\
& y=(\rho) \mathrm{W}_{\mathrm{y}}+X_{2}\left(\beta_{2}\right)+\varepsilon \\
& y=(\rho) \mathrm{W}_{\mathrm{y}}+X_{3}\left(\beta_{3}\right)+\varepsilon
\end{aligned}
$$

$$
y=(\rho) \mathrm{W}_{\mathrm{y}}+X_{1}\left(\beta_{1}\right)+X_{2}\left(\beta_{2}\right)+X_{4}\left(\beta_{4}\right)+\varepsilon
$$

where $y$ is the KDE estimation value for each model for the spatial availability of the CHCs, i.e. $\log (10) ; W$ the matrix with $W_{Y}$ the spatially-lagged dependent variable for the spatial weight matrix $W ; X_{1}$ the number of unemployed; $X_{2}$ the number of people with a letter of poverty; $X_{3}$ the number of people with low-income occupation; $X_{4}$ the population density (control variable); the vector of error terms; the parameter indicating effect of spatially-lagged dependent variable (spatial autoregressive coefficient); and $\beta$ other parameters. All values here are per village. In our final model (Model 4), we also included the population density of the village as a predictor to adjust for scale differences based on village size. Due to the wide range and skewness of the density values of $\mathrm{CHCs}$ assigned to the centroid point of each village, we transformed the $\log 10$ values and used $\log$ density as the response variable in all models.

\section{Results}

The CHCs were found to be unevenly distributed in the Jakarta region, and this distribution did not appear to follow the needs of the population. The KDE map showed a high concentration of CHCs in central Jakarta and the eastern areas of western Jakarta (Figure 3A). In addition, the distribution of healthcare workers within the $\mathrm{CHCs}$ was found to differ strongly from the density of the CHCs themselves (Figure 3B).

The three maps in Figure 4 show slightly different density patterns for each type of healthcare worker: GP, midwife, and nurse. However, although the density of GPs generally followed the density of CHCs (Figure 3B), an additional concentration of GPs within southern Jakarta was noted. The spatial distribution of $\mathrm{CHC}$ based GPs was generally dispersed across the study area, but only

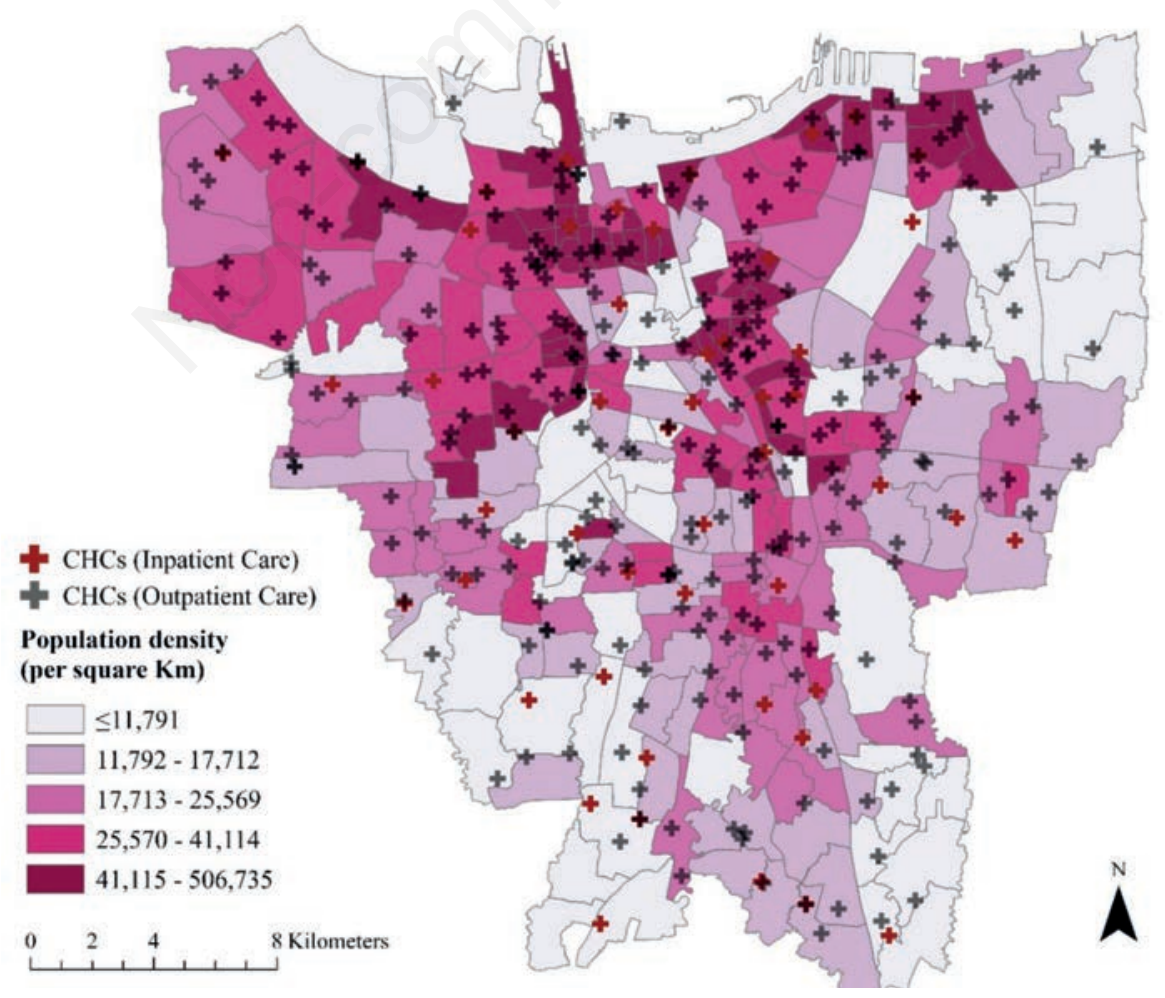

Figure 2. Distribution of community health centres (CHCs) along with the population density in each village. 
few GPs were observed in the north-eastern region (Figure 4). The distribution of midwives revealed a different pattern as they were mainly clustered in North Jakarta and West Jakarta, with a relative lack of concentration in Central Jakarta. Most nurses, on the other hand, were found to work within the CHCs in South and Central Jakarta, and also some parts of East Jakarta, which are both adjacent to Central Jakarta.

To analyse the spatial distribution of need for CHCs, we created cluster maps for each need variable based on local Moran's I statistics. All three low-income community variables had similar spatial high-high $(\mathrm{H}-\mathrm{H})$ patterns, with main concentrations in North Jakarta, especially in the Northeast and Northwest (Figure 5). The clusters represented villages with high numbers of unemployed, people with letters of poverty and low-income occupa- tions. Low-high (L-H) clusters of unemployment and low-income occupations were also found in North Jakarta villages, particularly in those along the Java Sea Coast. These villages had low concentrations of unemployed and/or low-income occupations even though they were surrounded by villages with high unemployment and low-income occupations.

Figure 5 also shows low-low (L-L) clusters that are mainly concentrated in villages in Central Jakarta and South Jakarta. These clusters of unemployed population and people with lowincome occupation are mainly located in certain villages where high- income populations tend to live. The L-L clusters of people who had obtained letters of poverty from their village office were mainly seen in South Jakarta and East Jakarta along with a few clusters of villages in the western part of the region.
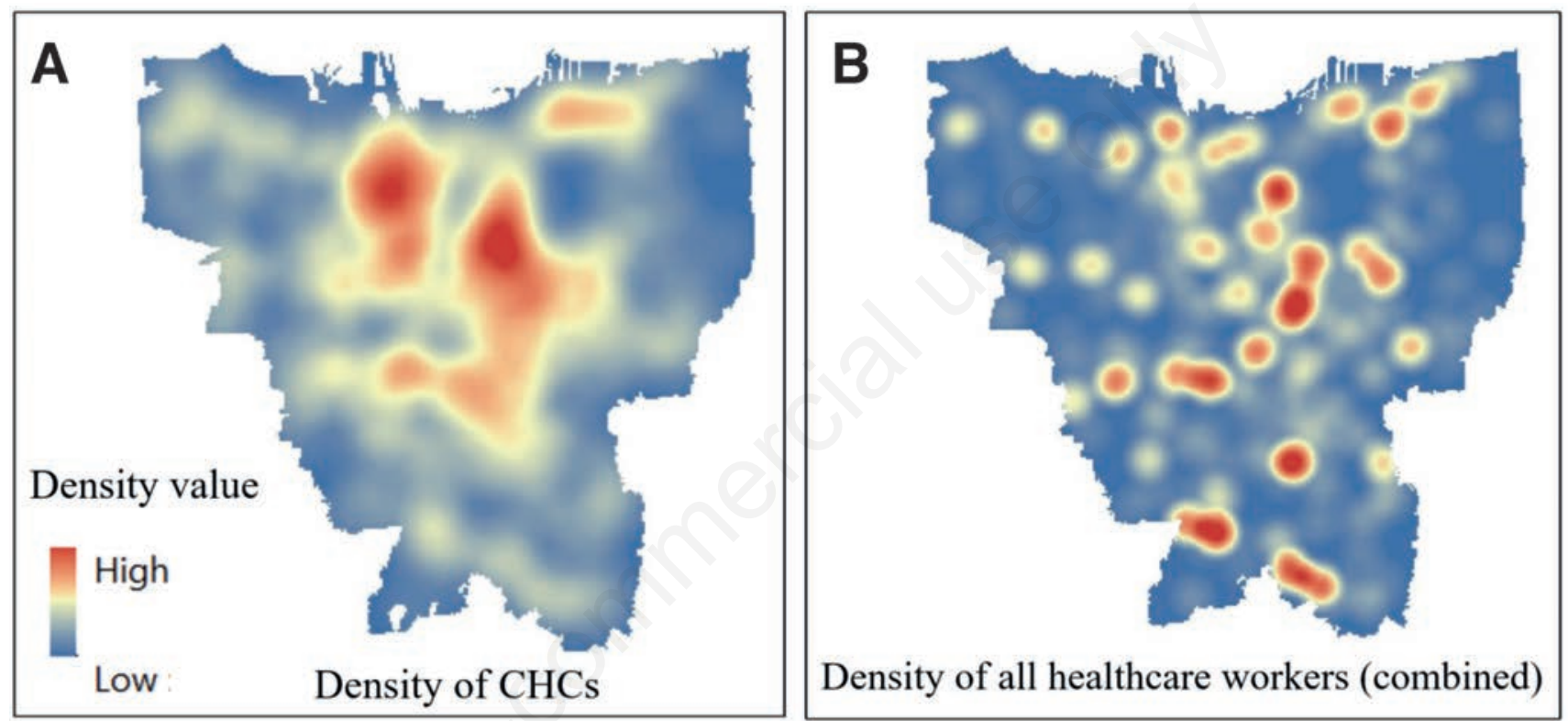

Figure 3. Kernel density maps of (A) community health centres (CHCs) and (B) healthcare workers.

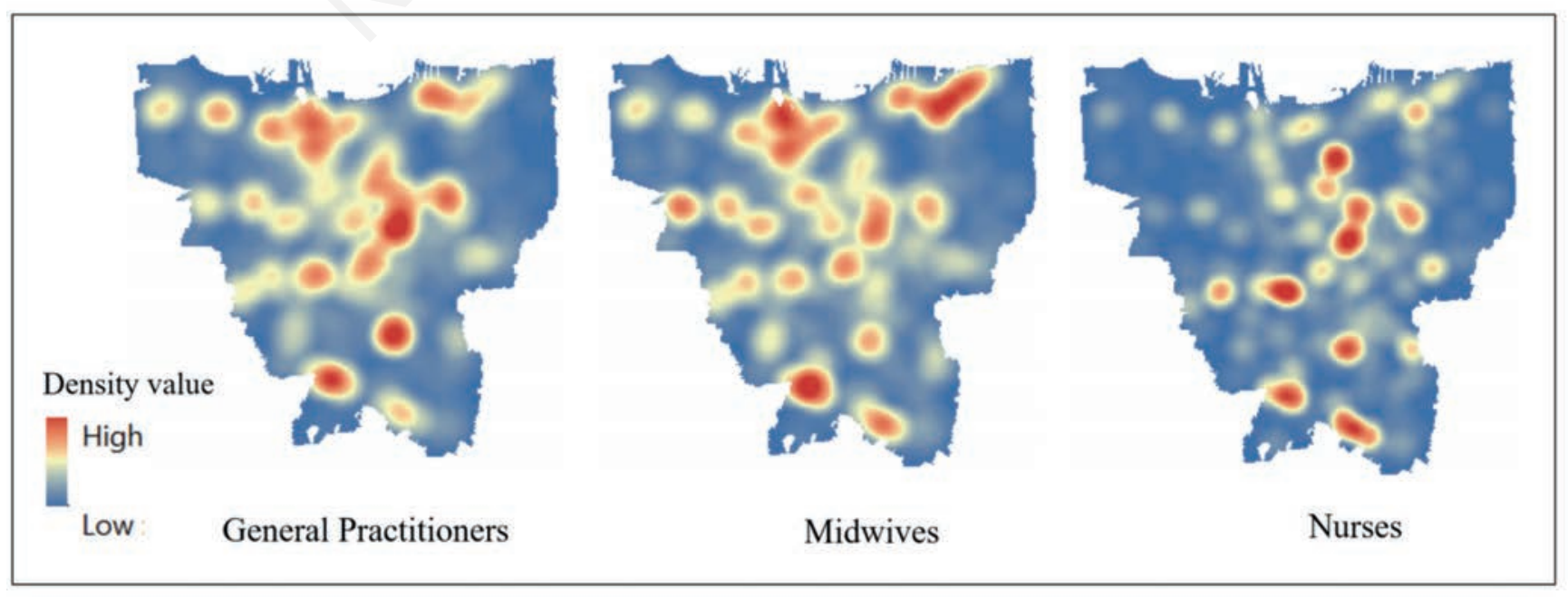

Figure 4. Kernel density maps of general practitioners, midwives and nurses. 
Table 1 shows the results of the spatial lag regression models which predict the density of $\mathrm{CHCs}$ as a function of each lowincome variable separately. Across the three models, unemployment was the only variable that had a negative association association with $\mathrm{CHC}$ density. However, although the results also showed an association for both people in low-income occupations and those with letters of poverty, the coefficients for these variables did not reach statistical significance.

Table 2 shows the results of the spatial lag regression models with the density of $\mathrm{CHCs}$ as the response variable and the three groups: people with unemployment, people who obtained letters of poverty, and the village population density as predictor variables. The results show that there is a significant spatial dependency in the model $(\mathrm{P}<0.001)$ indicating that the density value of $\mathrm{CHCs}$ at a location is strongly correlated with the density values at nearby locations. There was also a statistically significant inverse association between the density of CHCs and number of people unemployed.

\section{Discussion}

To better understand the distribution of the CHCs and healthcare workers, and to assess whether the availability of CHCs and healthcare workers meet the low-income population's need, we conducted a spatial and statistical analysis at the village level within an area with wide socioeconomic disparities. Most current

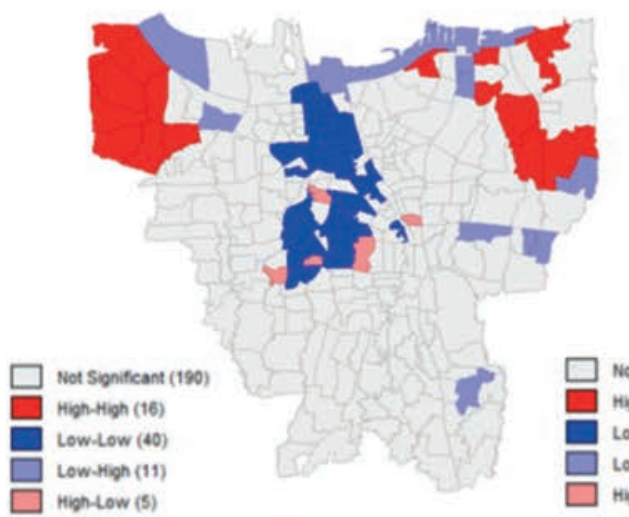

Unemployment
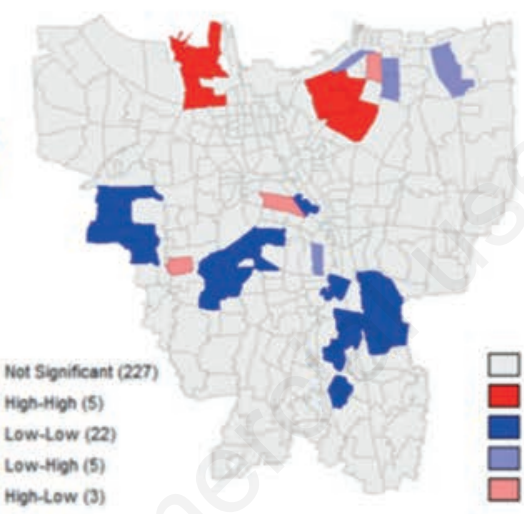

Migh-High (18)

Low-Low (39)

Low-High (11)

High-Low (3)

Letters of poverty

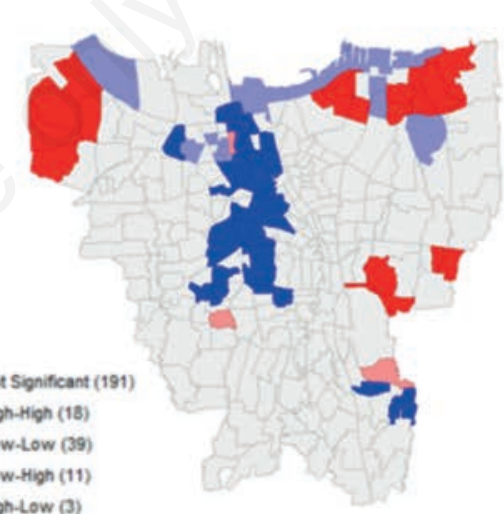

Low-income occupations

Figure 5. LISA cluster maps of poverty at the village level.

Table 1. Spatial regression of the log density of community health centres and variables of poverty at the village level.

\begin{tabular}{|c|c|c|c|c|c|c|}
\hline \multirow{2}{*}{ Low-income variable } & \multicolumn{2}{|c|}{ Model 1} & \multicolumn{2}{|c|}{ Model 2} & \multicolumn{2}{|c|}{ Model 3} \\
\hline & $\beta(\mathrm{SE})$ & P-value & $\beta(\mathrm{SE})$ & P-value & $\beta$ (SE) & P-value \\
\hline Unemployed & $-0.00002(0.00005)$ & $<0.001$ & & & & \\
\hline Letter of poverty & & & $-0.000005(0.000005)$ & 0.36 & & \\
\hline Low-income occupation & & & & & $-0.00002(0.00002)$ & 0.16 \\
\hline W & $0.197(0.03)$ & $<0.001$ & $0.22(0.03)$ & $<0.001$ & $0.21(0.03)$ & $<0.001$ \\
\hline
\end{tabular}

$\beta$, beta coefficient of the model; $\mathrm{SE}$, standard error; $\mathrm{W}$, spatial regression lag variable. All villages $(\mathrm{N}=262)$

Table 2. Spatial regression lag analysis of the log density of community health centres with unemployment, letter of poverty, and village population.

\begin{tabular}{lcc} 
Low-income variable & Model 4 & P-value \\
Unemployment & $-0.00003(0.000005)$ & $<0.001$ \\
Letter of poverty & $0.000003(0.000005)$ & 0.44 \\
\hline Control variable & $0.000001(0.0000004)$ & $<0.001$ \\
Population density & $0.19(0.03)$ & $<0.001$ \\
W & 0. & \\
\hline
\end{tabular}

$\beta$, beta coefficient of the model; $\mathrm{SE}$, standard error; $\mathrm{W}$, spatial regression lag variable. All villages $(\mathrm{N}=262)$. 
research on geographic inequality to health services in developing countries has examined the whole population, neglecting differences based on income or need. Studies investigating healthcare inequality with attention to low-income communities with poor access to healthcare services remain limited. Our research fills this gap by focusing on the low-income population living in a large metropolitan area.

The spatially uneven distribution of CHCs and the healthcare workers within them in the Jakarta region as seen in Figures 3 and 4 reflects the administrative structure as the CHCs are officially located and registered at the district level but more locally in villages, which are nested in districts. Indeed, the number of villages within districts varies depending on the size and population of the district. The lack of concentration of midwives in the central area, on the other hand, may be related to the greater availability of GPs and obstetricians, and the easier opportunity for hospital-based childbirth in the core of Jakarta's central area. That most nurses worked in South and Central Jakarta might be less of a problem as Central, South, and East Jakarta are adjacent to each other.

The strong positive association between CHC density and village population density indicates a broad correspondence between overall population and $\mathrm{CHC}$ availability. The spatial dependency of $\mathrm{CHC}$ density and nearby density discovered is expected because the $\mathrm{KDE}$ measure incorporates $\mathrm{CHCs}$ in nearby areas. Additionally, the inverse association between the density of $\mathrm{CHCs}$ and number of people unemployed further indicates that villages with high numbers of people unemployed have a lower density of CHCs confirming the results of Model 1.

Although the districts establish the $\mathrm{CHCs}$, their numbers and the healthcare workers within them do not follow the geographical distribution of the low-income population. Our findings show that the villages with more low-income residents, especially unemployed residents, often experience limited geographical access to healthcare services available at CHCs. Our results also show that the village-level $\mathrm{CHCs}$ often have few healthcare workers. Also, at smaller CHCs, rules and standards may be unmet due to the lack of healthcare workers. These problems are particularly acute in rural settings where the $\mathrm{CHCs}$ have even fewer healthcare workers (Strasser et al., 2016). A recent study (Mulyanto et al., 2019a) even suggests that local governments should subsidize travel costs for poor people living in rural regencies due to the extreme low rates of healthcare utilization found in those regencies.

Although the numbers of midwives and nurses have increased on a national basis, our findings indicate that the availability of healthcare workers does not always match population need. Also, as discussed in another study, Indonesia still faces a shortage of midwives and nurses within CHCs (Mahendradhata et al., 2017). Some provinces have tried to employ non-permanent or contract healthcare workers to meet the unmet demand (Heywood and Harahap, 2009a). Nurses have become the alternative to fill in the gap since nurses, especially non-permanent/contract nurses, are more affordable than GPs and midwives. From this study, we found that nurses are the dominant type of healthcare worker in all CHCs across Jakarta, especially in CHCs providing inpatient care. This is consistent with the results by Shields and Hartati (2003) who explored the nursing hiring process in Indonesia and found that nurses were viewed as 'doctors 'helpers' (p. 212), hired to help GPs in the CHCs. Indeed, at the village-level CHCs, nurses often oversee the CHC.

Besides North Jakarta, villages in West Jakarta showed some $\mathrm{H}-\mathrm{H}$ clusters both for the unemployment and low-income occupa- tion variables. H-H clusters of low-income occupation were also found in East Jakarta. Three areas: North Jakarta, West Jakarta and East Jakarta constantly showed high numbers of low-income communities. The clusters found in this study are consistent with the number of people living under the poverty line provided by Indonesia Statistics (2014). In our maps, villages in South and Central Jakarta consistently emerged as L-L clusters of lowincome variables indicating low concentrations of people in need of CHCs.

The negative coefficient for the unemployment variable in both the bivariate and adjusted spatial lag regression models shows that villages with high concentrations of unemployed population have fewer CHCs nearby. This provides strong evidence of an inverse care relationship (Hart, 1971; Watt, 2002): in which villages with higher need for services according to unemployed population have fewer CHCs locally available. As expected, the control variable - population density - had a positive association with the density of $\mathrm{CHCs}$, a sign that more $\mathrm{CHCs}$ are available in densely populated villages. Overall, the model suggests that CHCs are unevenly distributed and villages with high need face a lack of $\mathrm{CHCs}$ and healthcare workers within them. The inverse relationships between CHC availability and all three indicators of lowincome population indicate that villages with high numbers of poor and unemployed populations have relatively few $\mathrm{CHCs}$ nearby and that these villages need more CHCs to improve access.

This study has limitations as it did not address the role of and access to CHCs and healthcare workers in the rural areas, research that is urgently needed. Geographical issues also pose challenges in this study. The varying size of the districts and villages constrain the spatial distribution of CHCs and thus affect the KDE outcome. For instance, Central Jakarta is the smallest city among the 5 cities analysed, and its districts and villages are small in size. This, combined with the requirement of one $\mathrm{CHC}$ per district, leads to a higher density of CHCs in this area. Research shows that planning and allocating service facilities based on political districts can result in suboptimal location patterns characterized by inequalities in travel distance (Rushton, 1988). The edge effect is also an issue for those $\mathrm{CHCs}$ on the border with other provinces and along the coastline of the Java Sea. The edge effect is a common limitation in studies of healthcare accessibility (Shah et al., 2016). If we had included $\mathrm{CHCs}$ in neighbouring provinces in generating the density maps, the maps might show higher concentrations in the areas close to the provincial border.

Finally, we did not extend the analysis to volunteers and village health workers who often assist in CHCs. For instance, midwives from a $\mathrm{CHC}$ can work closely with healthcare volunteers who can help in providing services such as immunization and birth control. Extending this analysis to consider other types of healthcare workers in CHCs' networks is an important topic for future research. In addition, by focusing on low-income population, the spatial regression models do not incorporate other political or environmental factors that might impact the numbers and locations of CHCs. For example, $\mathrm{CHC}$ locations might be constrained by the availability and cost of land and infrastructure, and these variables should be considered in future work.

Despite these limitations, the results of this study may have implications for other developing countries where healthcare services are in short supply. Community health centre networks have been applied in other developing countries to address accessibility issues (Brauner-Otto et al., 2007; Yao et al., 2012). For example, in Nepal, low-income people utilize CHC's networks to get immu- 
nizations for their children (Archarya and Cleland, 2000). Community involvement is important in these CHC's networks and expanding community involvement in Indonesia's CHCs offers opportunities for developing more effective and responsive health services at the village level. It can also provide researchbased evidence to public health agencies in considering new locations of $\mathrm{CHCs}$ and placing healthcare workers within the CHCs. Such efforts can assist in improving healthcare services for poor people in the Jakarta region. In this way, our research can also be a model for other developing countries that face similar challenges with access to primary care.

\section{Conclusions}

There is a mismatch in healthcare services and delivery for low-income populations at the village level in Jakarta, Indonesia that needs to be addressed. Though $\mathrm{CHCs}$ and healthcare workers within them are generally available at the district level, the region still faces significant inequality, both spatially and socioeconomically, at the village level. The availability of CHCs and healthcare workers does not match with the populations who need their service. Availability and distance to facilities often pose significant barriers, especially at the city and district levels, which needs to be considered.

At the village level, spatial inequality is higher compared to the district level where policies require at least one $\mathrm{CHC}$ per district. The analysis presented here should assist policy makers in determining where new CHCs could be built to improve healthcare delivery and services. Also, it is suggested that Jakarta Department of Health coordinate with local public health districts in assigning healthcare workers to each $\mathrm{CHC}$ based on population need in order to improve access to essential health services for the low-income populations.

\section{References}

Acharya LB, Cleland J, 2000. Maternal and child health services in rural Nepal: does access or quality matter more? Health Policy Plan 15:223-9.

Anselin L, 1995. Local indicators of spatial association - LISA. Geograph Anal 27(2). Available from: https://dces.wisc. edu/wp-content/uploads/sites/128/2013/ 08/W4_Anselin 1995.pdf Accessed: June 2, 2021.

Awoyemi TT, Obayelu OA, Opaluwa HI, 2011. Effect of distance on utilization of health care services in rural Kogi State, Nigeria. J Hum Ecol 35:1-9.

Badan Pusat Statistik (BPS)/Indonesia Statistics, 2015. Jakarta Dalam Angka 2014 (Jakarta In Figures, 2014).

Badan Pusat Statistik (BPS)/Indonesia Statistics, 2020. Provinsi DKI Jakarta Dalam Angka 2020 (Jakarta In Figures, 2020). Available from: https://jakarta.bps.go.id/publication/2020/ 04/27/20f5a58abcb80a0ad2a88725/provinsi-dki-jakartadalam-angka-2020.html Accessed: June 06, 2021.

Brauner-Otto SR, Axinn WG, Ghimire DJ, 2007. The spread of health services and fertility transition. Demography 44:747-70.

Environmental Systems Research Institute (ESRI), 2017. How kernel density works. Available from: http://pro.arcgis.com/ nen/pro-app/tool-reference/spatial-analyst/how-kernel-densi- ty-works.htm Accessed: September 2, 2017.

Entwisle B, Rindfuss RR, Walsh SJ, Evans TP, Curran SR, 1997. Geographic information systems, spatial network analysis, and contraceptive choice. Demography 34:171-88.

Frederick WH, Worden RL (eds.), 1993. Indonesia: a country study. GPO for the Library of Congress, Washington, DC, USA.

GeoDa, 2017. Download GeoDa software, GeoDa release. Available from: https://geodacenter.github.io/download.html Accessed: September 15, 2017.

Guagliardo MF, 2004. Spatial accessibility of primary care: concepts, methods and challenges. Int J Health Geogr 3:3.

Hart JT, 1971. The inverse care law. Lancet 1:405-12.

Heywood P, Harahap NP, 2009a. Health facilities at the district level in Indonesia. Aust New Zealand Health Policy 6:13.

Heywood P, Harahap NP, 2009b. Public funding of health at the district level in Indonesia after decentralization - sources, flows and contradictions. Health Res Policy Syst 7:5.

Heywood P, Choi Y, 2010. Health system performance at the district level in Indonesia after decentralization. BMC Int Health Hum Rights 10:3.

Higgs G, 2004. A literature review of the use of GIS-based measures of access to health care services. Health Serv Outcomes Res Methodol 5:119-39.

Hoseini B, Bagheri N, Kiani B, Azizi A, Tabesh H, Tara M, 2018. Access to dialysis services: A systematic mapping review based on geographical information systems Iran. Geospat Health 13:577.

Indonesia Data Portal (IDP), 2017a. Jakarta number of people by type of occupations per village. Available from: http://data.go.id/dataset/jumlah-penduduk-berdasarkan-jenispekerjaan-per-kelurahan-dki-jakarta Accessed: October 17, 2017.

Indonesia Data Portal (IDP), 2017b. Jakarta number of people under the poverty line per village. Available from: http://data.go.id/dataset/jumlah-penduduk-miskin-menurutkabkota-dki-jakarta-2006-2010/resource/1547511f-3482406e-ade2-d02cfc4efa89 Accessed: October 17, 2017.

Indonesia Ministry of Health GIS Portal, 2017. Point data of community health center in DKI Jakarta Province. Available from: http://gis.depkes.go.id/ Accessed: September 1, 2017.

International Labor Organization (ILO), 2015. Indonesia: trends in wages and productivity. Asia-Pacific decent work decade 2006-2015. Available from: https://www.ilo.org/ wcmsp5/groups/public/—-asia/—-ro-bangkok/—-ilo-jakarta/documents/ publication/wcms_343144.pdf Accessed: January 20, 2020.

Jamtsho S, Corner R, Dewan A, 2015. Spatio-temporal analysis of spatial accessibility to primary health care in Bhutan. ISPRS Int J Geo-Inf 4:1584-604.

Macharia PM, Ouma PO, Gogo EG, Snow RW, Noor AM, 2017. Spatial accessibility to basic public health services in South Sudan. Geospat Health 12:510.

Mahendradhata Y, Trisnantoro L, Listyadewi S, Soewondo P, Marthias T, Harimurti P, Prawira J. 2017. The Republic of Indonesia health system review. Health System in Transit Vol. 7, No. 1: Asia Pacific Observatory on Health Systems and Policies.

McGrail MR, Humphreys JS, 2015. Spatial access disparities to primary health care in rural and remote Australia. Geospat Health 10:358. 
Ministry of Health (MOH), 2014. Community health center (CHC) basic data, DKI Jakarta Province based on December 2013 Dataset. Center for Data and Information (PUSDATIN).

Mulyanto J, Kunst AE, Kringos, 2019a. Geographical inequalities in healthcare utilisation and the contribution of compositional factors: A multilevel analysis of 497 districts in Indonesia. Health \& Place 60:102236.

Mulyanto J, Kunst AE, Kringos, 2019b. The evolution of incomerelated inequalities in healthcare utilisation in Indonesia, 19932014. PLoS One 14:e0218519.

Paul J, Edwards E, 2018. Temporal availability of public health care in developing countries of the Caribbean: an improved two-step floating catchment area method for estimating spatial accessibility to health care. Int J Health Plann Mgmt 34:536-56.

Ranga V, Panda P, 2014. Spatial access to in-patient health care in northern rural India. Geospat Health 8:545-56.

Ruktanonchai CW, Nilsen K, Alegana VA, Bosco C, Ayiko R, 2018. Temporal trends in spatial inequalities of maternal and newborn health services among four east African countries, 1999-2015. BMC Public Health 18:1339.

Rushton G, 1988. The Roepke lecture economic geography location theory, location-allocation models, and service development planning in the third world. Econ Geogr 64:97-120.

Shah TI, Bell S, Wilson K, 2016. Spatial accessibility to health care services: identifying under-serviced neighbourhoods in Canadian urban areas. PLoS One 11:e0168208.

Shaw S, Sahoo H, 2020. Accessibility to primary health centre in tribal district of Gujarat, India: application of two step floating catchment area model. GeoJ 85:505-14

Shi X, 2010. Selection of bandwidth type and adjustment side in kernel density estimation over in homogeneous backgrounds.
Int J Geogr Inf Sci 24:643-60.

Shields L, Hartati LE, 2003. Nursing and health care in Indonesia. J Adv Nursing 44:209-16.

Strasser R, Kam SM, Regalado SM, 2016. Rural health care access and policy in developing countries. Ann Rev Public Health 37:395-412.

van de Walle D, 1994. The distribution of subsidies through the public health services in Indonesia, 1978-87. World Bank Econ Rev 8:279-309.

Watt G, 2002. The inverse care law today. Lancet 360:252-4.

Woldemichael A, Takian A, Akbari Sari A, Olyaeemanesh A, 2019. Availability and inequality in accessibility of health centrebased primary healthcare in Ethiopia. PLoS One 14:e0213896.

World Bank, 2019. The World Bank in Indonesia. Available from: https://www.worldbank.org/en/country/indonesia/overview Accessed: January 30, 2020.

Xiong X, Li Luo L, 2017. Use of geographical information systems for delimiting health service areas in China. Geospat Health 12:486.

Yang D, Goerge R, Mullner R, 2006. Comparing GIS-Based methods of measuring spatial accessibility to health services. J Med Syst 30:23-32.

Yao J, Murray AT, Agadjanian V, Hayford S, 2012. Geographic influences on sexual and reproductive health service utilization in rural Mozambique. Appl Geogr 21:601-7.

Yao J, Murray AT, Agadjanian V, 2013. A geographical perspective on access to sexual and reproductive health care for women in rural Africa. Soc Sci Med 96:60-8.

Yusvirazi L, Ramlan AAW, Hou PC, 2018. State of emergency medicine in Indonesia. Emerg Med Australas 30:820-6. 